This impeccably produced book, with interesting line drawings, was completed by his widow from unfinished manuscripts. It has three main topics: a general appraisal of the behaviour of certain vertebrate predators mainly in the United States, a general account of the facts accumulated by Errington in his life's work on quail and muskrats, and a series of reviews of other work on these and similar species and of selected aspects of predation. These accounts lead to the philosophy that wilderness should be conserved with predators and predation as a part of life. It is essentially a popular book and pleasant to read, presenting all information in essay form without tabulated data, presumably in an attempt to present information in a way acceptable to the sportsman and amateur naturalist.

Errington's credo is now well known. His conclusions emphasise that vertebrate predators do not control the numbers of their prey species, that they are essentially opportunists killing, for preference, vulnerable surplus prey as these become available to them and only tackling the relatively secure remainder under conditions of extreme food shortage. Most vertebrate ecologists will agree with these conclusions - will the sportsman also agree? If he is not already convinced, this book may not persuade him. Anecdote is insufficiently supported by documented fact. Assessment of facts presented depends too often on knowledge of the original papers. This is unfortunate and a serious criticism of the presentation. In addition the style is long-winded and simple facts are sometimes lost in a complicating wealth of words. This is doubly a pity since Errington was a pioneer in this field and the duration and continuity of his observations are unique. (He had data on quail from 1932 for over 20 years and on muskrats from 1932 to 1947 with additional information for subsequent years.) Unfortunately a clear, simple account of his data and their interpretation is still lacking, and this book does not adequately fill the gap. Its most interesting new items are chapters on the inter-relationships of different predator species and on predation on waterfowl; and these bring together some interesting data not widely known to European ecologists. The main achievement of Errington's work is that his ideas have contributed greatly to the thinking of his successors, and this book will be useful in widening interest in these ideas as they are developed, and in stimulating new research on predation.

DAVID JENKINS

\title{
Pesticides and Pollution by Kenneth Mellanby. Collins, New
} Naturalist, 30 s.

This is a clearly written and well balanced book on a subject of wide importance. It illuminates by dispelling ignorance and avoiding alarmist views, although at the same time indicating by what a narrow margin this country has escaped the devastating damage to wild life which has occurred elsewhere, notably in the United States and Canada. Dr Mellanby covers all aspects of pollution: of air, including the effects of radiation, of fresh waters, of the sea, and the effects on terrestrial life of the wide array of herbicides, fungicides and, above all, insecticides which have been responsible - and we must be clear about this - for so much of the increase in agricultural productivity, despite reduced manpower, in recent years.

Some of the effects of chemicals are indirect; by the quite incidental elimination of a predator upon it, a minor pest may become a major pest. We shall never be able to forecast the full effect of any chemical until we can find our way through the intricacy of ecological relationships. But the persistent organo-chlorines are, as Dr Mellanby notes, the major villains. Continuous accumulation through the bodies of successive members of a food chain leads to mass destruction of spectacular predators such as golden eagles and peregrines. Fortunately preventive action has been taken just in time. Dr Mellanby is extremely well informed on this 
aspect and well balanced in his estimates of present damage and future risks. He is really more concerned with air pollution where smoke reduction is accompanied by increase in $\mathrm{SO}_{2}$ with the petrol engine more lethal than the diesel. $\mathrm{He}$ is less informative about pollution of fresh waters (where indeed there are other sources of knowledge) and still less about the sea. However, the effects of the Torrey Canyon may well be more beneficial than harmful if we are shocked into organisation of adequate measures against further risks of oil pollution.

Within the covers of a relatively short book, the author could hardly have done better.

C. M. YONGE

\section{Darwin and Henslow. The growth of an idea. Letters 1831-1860. Edited by Nora Barlow. John Murray, 35s.}

This is a happy book. It consists of letters forthright and as fresh as yesterday. The first explodes with the zest of a young naturalist who has just completed his formal education. Where it will lead, who could tell ? They proceed with gathering experience, wisdom and bliss until, after 30 years, there comes one of the least known, yet one of the greatest, Letter 114; it culminates the triumphant friendship which established modern thought. We see the vivacious actor, Charles Darwin, impromptu in his career; we hear the studious prompter, John Stevens Henslow, reminding him of his audience, almost as author directing the drama. Who was this divine who steered the young man from the Church into a path that was mistaken for unholy and vindicated him? Footnotes, bibliography and appendices do not wither with erudition but magnify the intimacy of these two manifold lives which grow in the imagination.

Various of these letters have appeared before, but not in this stark sequence which is their thrill. The fun of life runs through them all, for that recluse old man draped in his black cloak had the sprightliest mind. If one has not read The Voyage of the Beagle or The Origin of Species, these letters will entice; and, having enjoyed this little book, one will need possess it.

E. J. H. CORNER

\section{Great Waters, by Alister Hardy. Collins, 63s.}

This book is based on Sir Alister Hardy's journal when he was Chief Zoologist aboard the RRS Discovery, a sailing ship with only a steam auxiliary, during an expedition to the Southern Ocean in 1925-27. The aim of the voyage was to study the biology of whales and the relevant oceanography of the seas in the region bounded by the Falkland Islands, South Georgia, the South Orkneys, South Shetlands and Cape Horn, with regard to the preservation of the whaling industry. The work was to be analogous to that carried out by fishery scientists in European seas since about 1900.

The narrative of the voyage is broken in places by accounts of the results obtained, largely in the form of summaries of the Discovery Reports; even so, it seems to drag at times, but it does show well the atmosphere of this pioneer voyage: the tediously long spells of hard routine work, the frustrations due to bad weather, the hazards of ice and shortage of fuel, the need for improvisation with scientific equipment and so on. Sir Alister's synthesis of the results shows clearly the ecosystem which supported the huge whale stocks. He also gives us an eye-witness account of the whaling industry in the $1920 \mathrm{~s}$, but he deals too briefly with the question of how it was able to develop so as to reduce some species to near extinction.

Fisheries scientists aim to collect enough data from which to calculate the best sustainable yield from a stock of whales or fish. In the case of the Southern Ocean whales it was difficult to carry out tagging and ageing, two of the techniques used 